\begin{tabular}{|c|c|}
\hline & $\begin{array}{l}\text { Volume } 3 \text { Nomor. 1, April } 2018 \\
\text { P -ISSN : 2541-1179, E-ISSN : 2581-1711 } \\
\text { Ojs :http://journal.uin-alauddin.ac.id/index.php/instek/index }\end{array}$ \\
\hline 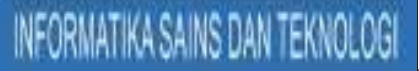 & Email : instek@uin-alauddin.ac.id \\
\hline
\end{tabular}

\title{
DESAIN SISTEM KANDANG AYAM BROILER TIPE CLOSE HOUSE BERDASARKAN PARAMETER SUHU DAN KELEMBABAN
}

\author{
A.Muhammad Syafar \\ Dosen Jurusan Teknik Informatika \\ Fakultas Sains \& Teknologi UIN Alauddin Makassar \\ E-mail : andimuhammadsyafar@gmail.com
}

\begin{abstract}
ABSTRAK
Kajian penelitian ini menitikberatkan pada sistem kandang Ayam broiler tipe close house. Penelitian ini bertujuan untuk mendesain sistem kandang ayam boiler tipe close house berdasarkan parameter suhu dan kelembaban dengan menggunakan mikrokontroller.

Metode penelitian yang digunakan dalam proses desain adalah penelitian kualitatif dengan eksperimental. Proses pengujian yang dilakukan adalah pengujian blackbox. Hasil pengujian sensor DHT11 diperoleh nilai rata-rata suhu $31,5^{\circ} \mathrm{C}$ dan rata-rata kelembaban $70 \%$. Sedangkan pengujian dengan thermometer diperoleh nilai rata-rata suhu $31^{\circ} \mathrm{C}$ dan rata-rata kelembaban $69 \%$. Dimana hasil dari penelitian ini adalah model desain prototype berguna dalam pemanfaatan kestabilan kandang pada suhu $31^{\circ} \mathrm{C}-35^{\circ} \mathrm{C}$ dengan kelembaban $50 \%-70 \%$, selanjutnya diatur ketersediaan pakan dalam wadah dan mengatur penerangan kandang secara otomasi.
\end{abstract}

Kata kunci: Ternak Ayam Broiler, Mikrokontroler, Prototype, Suhu, Kelembaban, Pakan, Penerangan, dan Otomasi.

\section{I.PENDAHULUAN}

Ayam ras pedaging disebut juga broiler, merupakan hasil persilangan antara ayam Cornish dari Inggris dengan ayam White Plymouth Rock dari Amerika. Ayam broiler adalah ayam ras yang mampu tumbuh cepat sehingga dapat menghasilkan daging dalam waktu relatif singkat (Murtidjo, 1987).

Peternak ayam broiler di Indonesia pada umumnya menggunakan jenis kandang terbuka dan masih menggunakan cara manual dalam proses pemeliharaan ternaknya seperti dalam mengatur suhu kandang, peternak sulit mengetahui informasi suhu pada kandang. Terlebih ketika musim pancaroba tiba, cuaca yang tidak menentu akan menyebabkan suhu kandang tidak optimal dan berubah-ubah. 


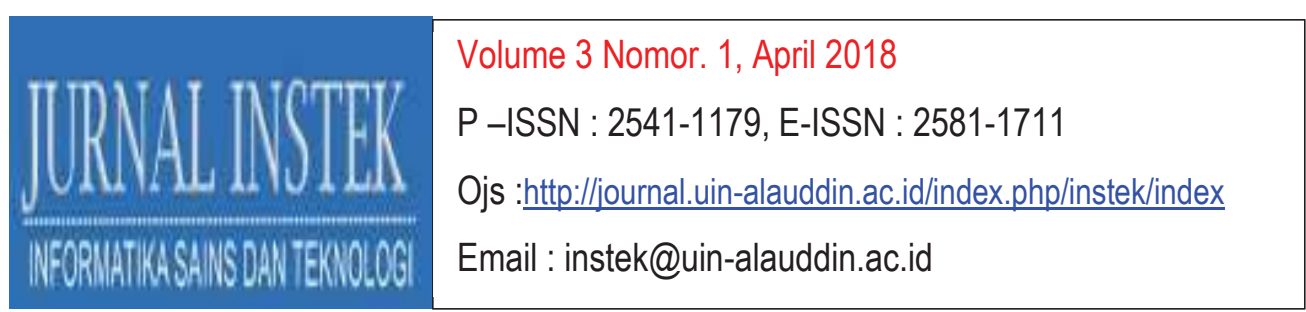

Ada beberapa penelitian terdahulu terkait judul penelitian adalah sebagai berikut. Menurut Ridhamuttaqin, Trisanto dan Nasrullah (2013) pada penelitian yang berjudul "Rancang Bangun Model Sistem Pemberi Pakan Ayam Otomatis Berbasis Fuzzy Logic Control”. Tujuan dari penelitian ini adalah untuk membuat sistem pemberi pakan ayam secara otomatis. Sedangkan pada penelitian yang akan dirancang adalah berupa pengembangan sistem yang dapat mengatur serta menjaga kestabilan suhu dan kelembaban ruang kandang, mengatur ketersediaan pakan dan penerangan (lampu) pada kandang.

Nasution (2015) pada penelitian yang berjudul "Rancang Bangun Alat Pemberi Pakan dan Pengatur Suhu Otomatis untuk Ayam Pedaging berbasis Programmable Logic Controller pada Kandang Tertutup". Tujuan dari penelitian ini adalah untuk membantu para peternak ayam pedaging di Indonesia dalam mengelola ternaknya dari segi pemberian pakan dan dari penjagaan suhu pada kandang ayam tersebut. Namun yang menjadi perbedaan adalah teknologi yang digunakan dari penelitian sebelumnya menggunakan Programmable Logic Controller (PLC) sedangkan pada penelitian yang akan dirancang menggunakan mikrokontroler Arduino Mega dan menambahkan fungsi pengaturan penerangan(lampu) pada kandang.

Berdasarkan permasalahan diatas, maka akan dibuat suatu alat perancangan sistem pemeliharaan ternak ayam broiler berbasis mikrokontroler pada kandang tertutup sebagai solusi bagi para peternak dalam memelihara ternak ayam broiler berdasarkan parameter suhu dan kelembaban.

\section{METODE PENELITIAN}

\section{A. Jenis Dan Lokasi Penelitian}

Dalam melakukan penelitian ini, jenis penelitian yang digunakan adalah penelitian kuantitatif dengan metode eksperimental. 
Volume 3 Nomor. 1, April 2018

P-ISSN : 2541-1179, E-ISSN : 2581-1711

Ojs :http://journal.uin-alauddin.ac. id/index.php/instek/index

Email : instek@uin-alauddin.ac.id

\section{B.Instrumen Penelitian}

Adapun instrument penelitian yang digunakan dalam penelitian yaitu:

\section{Perangkat Keras}

Perangkat keras yang digunakan untuk mengembangkan dan mengumpulkan data pada aplikasi ini adalah sebagai berikut:

a) Laptop Asus dengan spesifikasi Prosesor Intel(R) Celeron(R), CPU $107 \mathrm{U}$ (a) 1.50, RAM 4 GB.

b) Printer canon ip 2770

c) Lampu pijar 100 watt (1 buah)

d) Lampu LED 5 watt (1 buah)

e) Tempat pakan ukuran tinggi $17 \mathrm{~cm}$ (1 buah)

f) Rangkaian driver motor DC (1 buah)

g) Motor DC

h) Sensor DHT11 (1 buah)

i) Sensor Light Dependent Resistor (LDR) (2 buah)

j) Rangkaian LCD ukuran 16 × $2 \mathrm{~cm}$ (1 buah)

k) Rangkaian relay 4 channel (1 buah)

1) Kipas ukuran $12 \times 12 \mathrm{~cm} 12$ volt (2 buah)

m) Kabel jumper

n) Kabel audio

o) Platform kandang ayam broiler closed house ukuran 45x45x45 cm.

\section{Perangkat Lunak}

Adapun perangkat lunak yang digunakan dalam aplikasi ini adalah sebagai berikut:

a) Sistem Operasi Windows 10, 64 bit.

b) Arduino Mega 2560 (Software Programing Module Arduino ). 


\begin{tabular}{|c|c|}
\hline 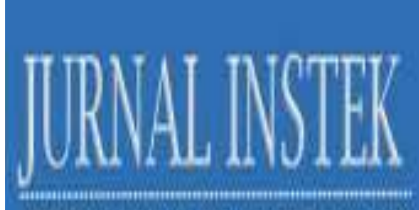 & $\begin{array}{l}\text { Volume } 3 \text { Nomor. 1, April } 2018 \\
\text { P -ISSN : 2541-1179, E-ISSN : 2581-1711 } \\
\text { Ojs :http://journal.uin-alauddin.ac.id/index.php/instek/index }\end{array}$ \\
\hline NFORNATIKASA NSOANN TENOLOOE & Email : instek@uin-alauddin.ac.id \\
\hline
\end{tabular}

\section{C.Perancangan Alat}

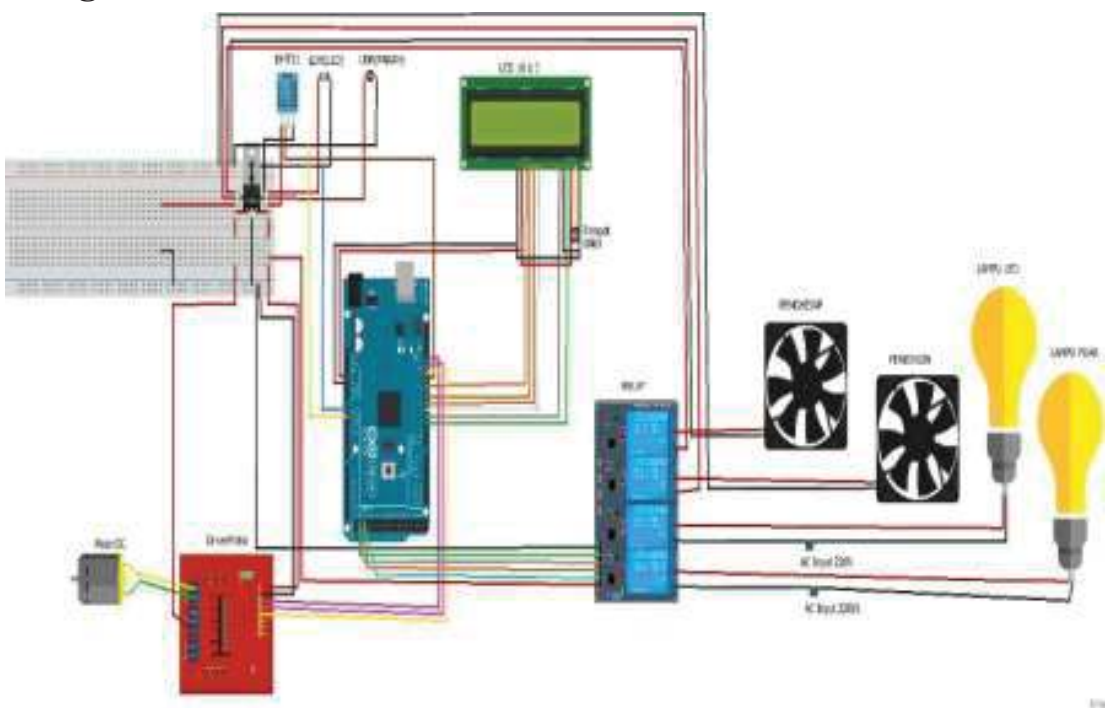

Gambar 1.Perancangan Komponen Alat Elektronik

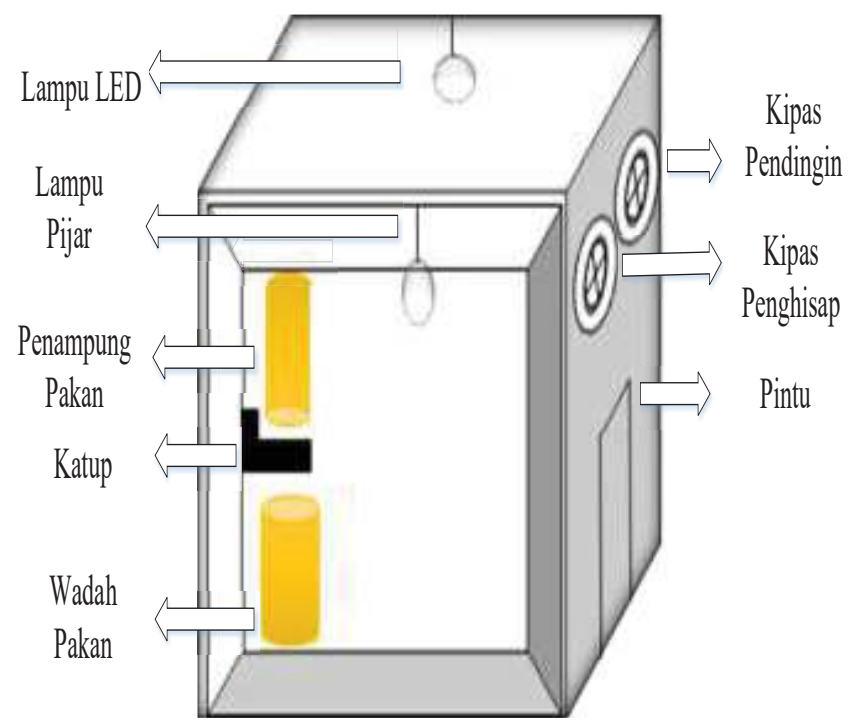

Gambar 2. Rangkaian Mekanik Prototype Kandang 
Volume 3 Nomor. 1, April 2018

P-ISSN : 2541-1179, E-ISSN : 2581-1711

Ojs :http://journal.uin-alauddin.ac.id/index.php/instek/index

Email : instek@uin-alauddin.ac.id

\section{D.Proses Pengujian Sistem}

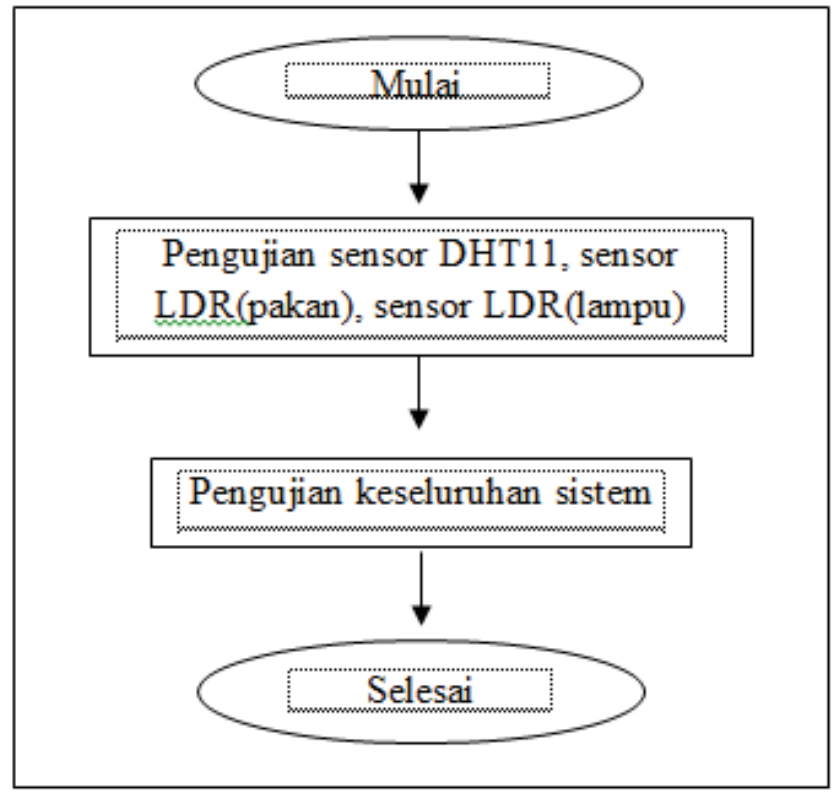

Gambar 3. Langkah Pengujian Sistem

\section{III.HASIL DAN PEMBAHASAN}

\section{A. Implementasi Alat}

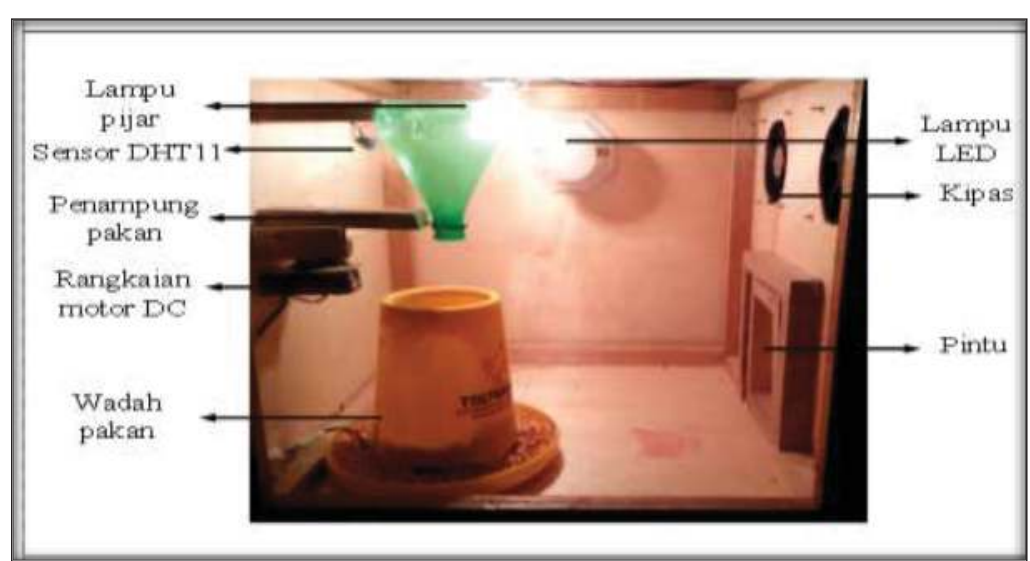

Gambar 4. Prototype Kandang Tampak Depan 

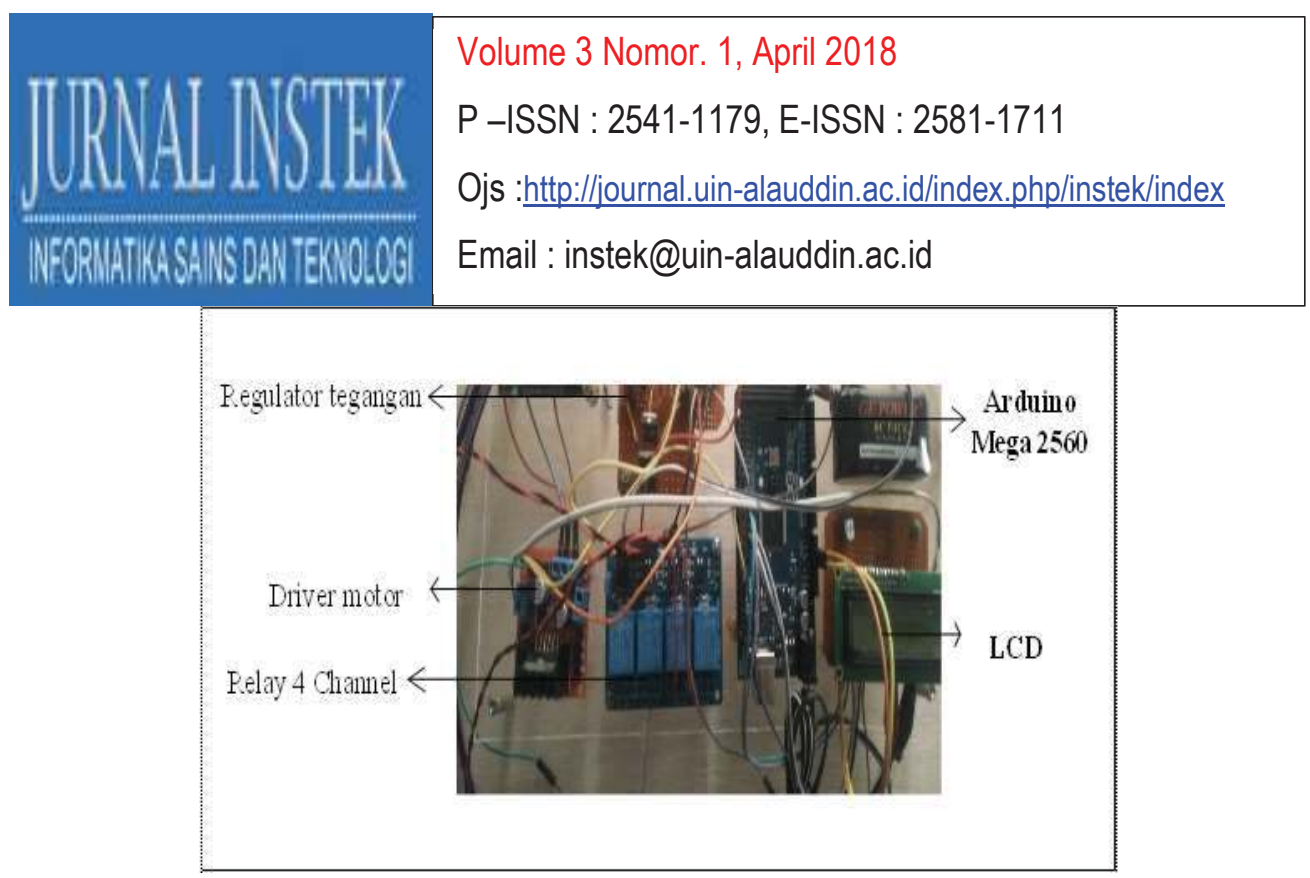

Gambar 5. Rangkaian Sistem Elektronika

\section{B. Hasil Pengujian}

\section{Pengujian Sensor DHT11}

Tabel 1. Data Pengamatan Sensor DHT11 dan Thermometer

\begin{tabular}{|c|c|c|c|c|c|c|}
\hline \multirow{2}{*}{ No. } & \multicolumn{2}{|c|}{ DHT11 } & \multicolumn{2}{c|}{ Thermometer } & \multicolumn{2}{c|}{ Selisih } \\
\cline { 2 - 7 } & Suhu & Kelembaban & Suhu & Kelembaban & Suhu & Kelembaban \\
\hline 1 & $30^{\circ} \mathrm{C}$ & $73 \%$ & $30^{\circ} \mathrm{C}$ & $71 \%$ & $0^{\circ} \mathrm{C}$ & $2 \%$ \\
\hline 2 & $31^{\circ} \mathrm{C}$ & $71 \%$ & $31^{\circ} \mathrm{C}$ & $70 \%$ & $0^{\circ} \mathrm{C}$ & $1 \%$ \\
\hline 3 & $32^{\circ} \mathrm{C}$ & $69 \%$ & $31^{\circ} \mathrm{C}$ & $68 \%$ & $1^{\circ} \mathrm{C}$ & $1 \%$ \\
\hline 4 & $33^{\circ} \mathrm{C}$ & $67 \%$ & $32^{\circ} \mathrm{C}$ & $67 \%$ & $1^{\circ} \mathrm{C}$ & $0 \%$ \\
\hline Jumlah & $126^{\circ} \mathrm{C}$ & $280 \%$ & $124^{\circ} \mathrm{C}$ & $276 \%$ & $2^{\circ} \mathrm{C}$ & $4 \%$ \\
\hline Rata-rata & $31,5^{\circ} \mathrm{C}$ & $70 \%$ & $31^{\circ} \mathrm{C}$ & $69 \%$ & $0,0^{\circ} \mathrm{C}$ & $1 \%$ \\
\hline
\end{tabular}

Perhitungan data tersebut diperoleh dari hasil analisa perhitungan berikut ini:

- Rata-rata suhu dan kelembaban DHT11 dan Thermometer

1) Suhu rata-rata DHT11 $=\mathrm{X}=\frac{\sum X n}{n}=\frac{126}{4}=31,5$

2) Suhu rata-rata Thermometer $=\mathrm{Y}=\frac{\sum X n}{n}=\frac{124}{4}=31$

3) Kelembaban rata-rata DHT11 $=\mathrm{x}=\frac{\sum x n}{n}=\frac{280}{4}=70$

4) Kelembaban rata-rata Thermometer $=y=\frac{\sum X n}{n}=\frac{276}{4}=69$ 


\begin{tabular}{|c|c|}
\hline 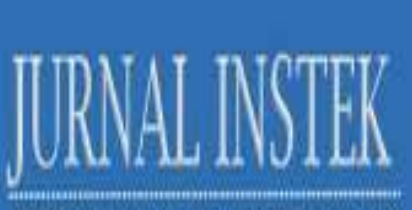 & $\begin{array}{l}\text { Volume } 3 \text { Nomor. 1, April } 2018 \\
\text { P -ISSN : 2541-1179, E-ISSN : 2581-1711 } \\
\text { Ojs :http://journal.uin-alauddin.ac.id/index.php/instek/index }\end{array}$ \\
\hline MEORMATIKASA NSOAN TENNOLOCI & Email : instek@uin-alauddin.ac.id \\
\hline
\end{tabular}

- Selisih antara suhu dan kelembaban rata-rata DHT11 dan Thermometer

1) Suhu $=X-Y=31,5-31=0.5$

2) Kelembaban $=x-y=70-69=1$

Tabel 2.Pengujian sensor DHT11

\begin{tabular}{|c|c|c|c|}
\hline Suhu & Kelembaban & Kondisi & Aksi \\
\hline$<31{ }^{\circ} \mathrm{C}$ & $>70 \%$ & Tidak stabil & Lampu pijar menyala \\
\hline $31-32^{\circ} \mathrm{C}$ & $50 \%-70 \%$ & Stabil & $\begin{array}{c}\text { Lampu pijar menyala, } \\
\text { kipas penghisap menyala }\end{array}$ \\
\hline $33-35^{\circ} \mathrm{C}$ & $50 \%-70 \%$ & Stabil & $\begin{array}{c}\text { Lampu pijar dan semua } \\
\text { kipas menyala }\end{array}$ \\
\hline$>35^{\circ} \mathrm{C}$ & $<50 \%$ & Tidak Stabil & $\begin{array}{c}\text { Lampu pijar mati dan } \\
\text { semua kipas menyala }\end{array}$ \\
\hline
\end{tabular}

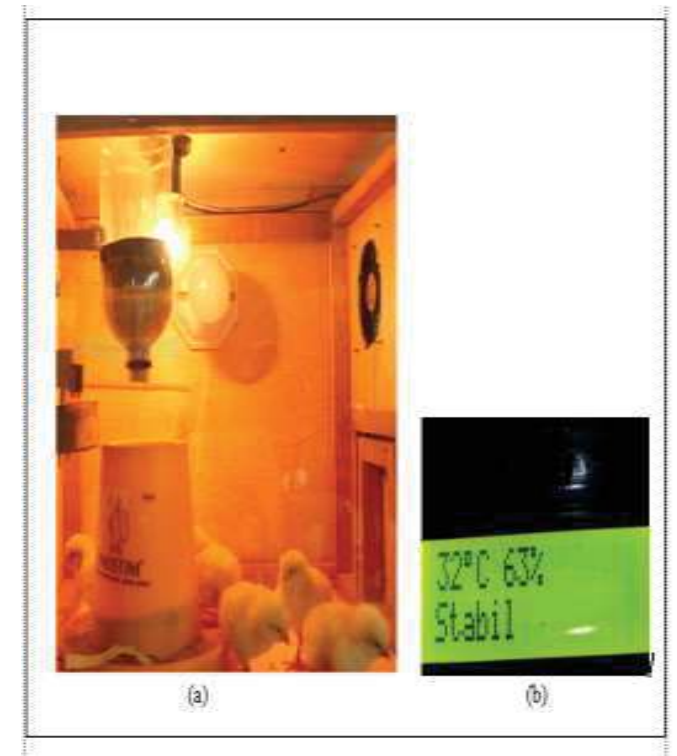

Gambar 6. Pengujian Sensor DHT11 (Kondisi Stabil) 
Volume 3 Nomor. 1, April 2018

P-ISSN : 2541-1179, E-ISSN : 2581-1711

Ojs :http://journal.uin-alauddin.ac.id/index.php/instek/index

Email : instek@uin-alauddin.ac.id

\section{Pengujian Sensor LDR}

Pengujian sensor dilakukan menggunakan aplikasi arduino untuk mengetahui nilai resistansinya.

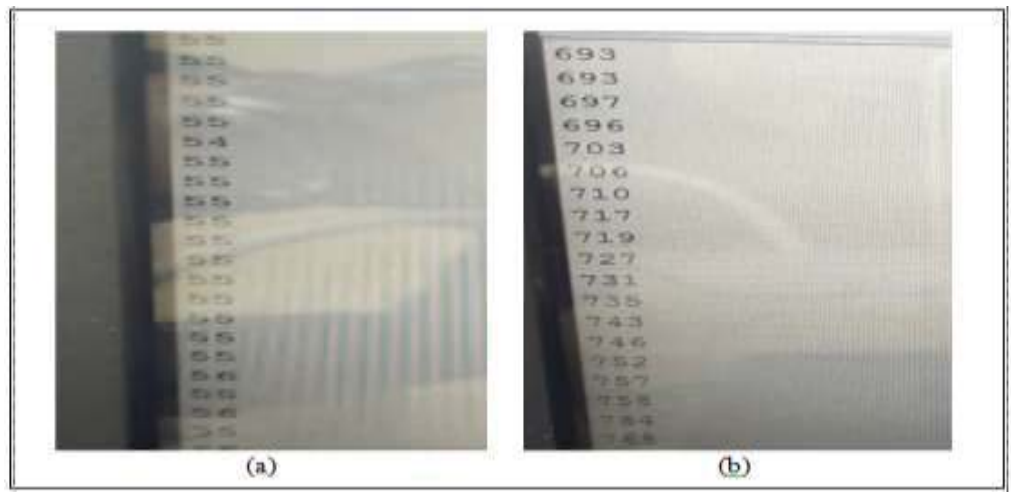

Gambar 7. Pengujian Sensor LDR

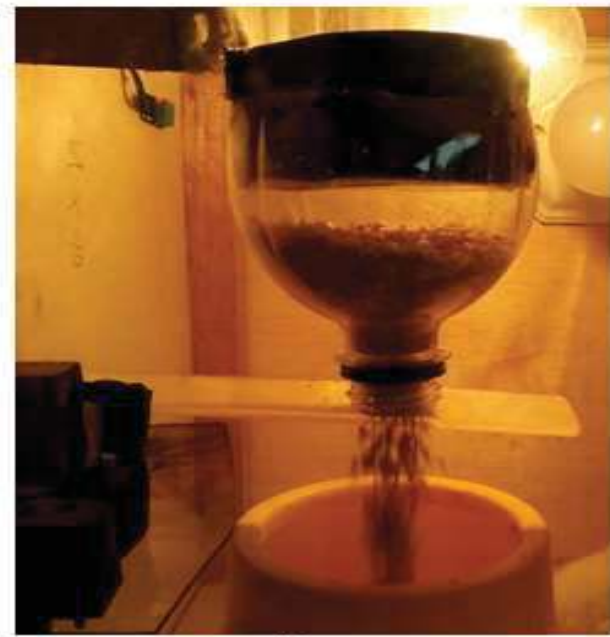

(a)

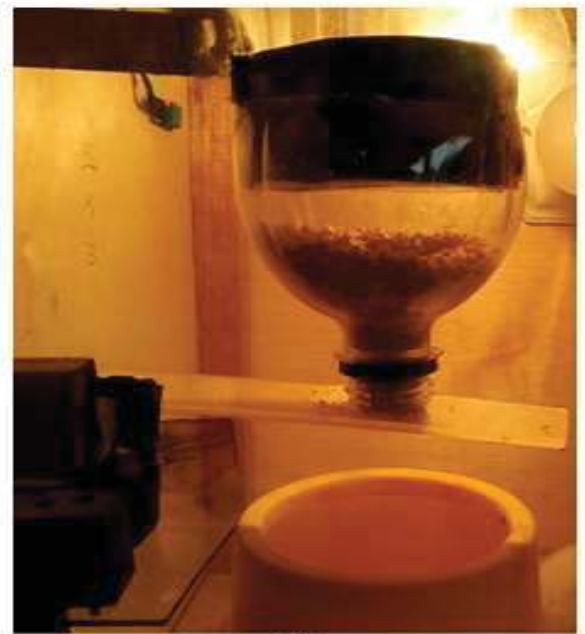

(b)

Gambar 8. Pengujian Sensor LDR (Pakan) 
Volume 3 Nomor. 1, April 2018

P-ISSN : 2541-1179, E-ISSN : 2581-1711

Ojs :http://journal.uin-alauddin.ac.id/index.php/instek/index

NEORUATIKASANSOAN TENOOCOE

Email : instek@uin-alauddin.ac.id

\section{IV.PENUTUP}

\section{A. Kesimpulan}

Berdasarkan hasil penelitian yang telah dilakukan didapat kesimpulan sebagai berikut :

1. Prototype sistem pemeliharaan ternak ayam broiler pada kandang tertutup secara otomasi telah berhasil dirancang dan dibuat dengan menggunakan mikrokontroler Arduino Mega 2560.

2. Pengujian prototype kandang secara keseluruhan menunjukkan bahwa penggunaan sensor DHT11 menghasilkan pengukuran suhu dan kelembaban yang cukup akurat sehingga pada saat pengujian, sistem berjalan dengan baik dan bisa menjaga kestabilan suhu dan kelembaban sesuai dengan zona nyaman ayam broiler periode starter yaitu suhu $31^{\circ} \mathrm{C}-$ $35^{\circ} \mathrm{C}$ dan kelembaban $50-70 \%$. Demikian pula dengan penggunaan sensor LDR untuk mengatur ketersediaan pakan dalam wadah dan LDR untuk mengatur on-off lampu berjalan sesuai dengan fungsi yang telah ditetapkan.

3. Hasil pengujian sensor DHT11 diperoleh nilai rata-rata suhu $31,5^{\circ} \mathrm{C}$ dan rata-rata kelembaban $70 \%$. Sedangkan pengujian dengan thermometer diperoleh nilai rata-rata suhu $31^{\circ} \mathrm{C}$ dan rata-rata kelembaban $69 \%$. Dimana hasil dari penelitian ini adalah model desain prototype berguna dalam pemanfaatan kestabilan kandang pada suhu $31^{\circ} \mathrm{C}-35^{\circ} \mathrm{C}$ dengan

kelembaban $50 \%-70 \%$, selanjutnya diatur ketersediaan pakan dalam wadah dan mengatur penerangan kandang secara otomasi. 


\begin{tabular}{|c|c|}
\hline $\ln _{\mathbb{L}} \mathrm{L}$ & $\begin{array}{l}\text { Volume } 3 \text { Nomor. 1, April } 2018 \\
\text { P -ISSN : 2541-1179, E-ISSN : 2581-1711 } \\
\text { Ojs :http://journal.uin-alauddin.ac.id/index.php/instek/index }\end{array}$ \\
\hline 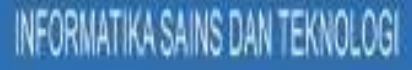 & Email : instek@uin-alauddin.ac.id \\
\hline
\end{tabular}

DAFTAR PUSTAKA

Ahmadi. 2008. Sistem Perkandangan Unggas. http://kandangclosedhouse. wordprees.com. Diakses pada 11 Maret 2018.

Belajar Listrik. 2017. Cara Memprogram Sensor DHT11 Suhu dan Kelembaban. http://belajarlistrik.com/cara-memprogram-sensor-dht11-suhu-kelembaban Diakses pada 15 September 2017.

Dasar Elektronika. 2012. LCD (Liquid Cristal Display). (http://elektronikadasar.web.id/lcd-liquid-cristal-display/). Diakses pada 18 September 2017.

Ecadio. 2017. Belajar dan Mengenal Arduino Mega. http://ecadio.com/belajardan-mengenal-Arduino-mega Diakses pada 3 september 2017.

Hazami, Syafi'I., Hardienata, Soewarto., dan Suriansyah, M. Iqbal. 2016. Model Pengatur Suhu Dan Kelembaban Kandang Ayam Broiler Menggunakan Mikrokontroler ATMega328 Dan Sensor DHT11. Skripsi. Universitas Pakuan.

Jayana, Christopher E., dan Harianto, Bagus. 2011. 28 Hari Panen Ayam Broiler. AgroMedia Pustaka. Jakarta.

Murtidjo, BA. 1987. Beternak Ayam Pedaging. Kanisius, Yogyakarta.

Nasution, Anwar Kholidi. 2015. Rancang Bangun Alat Pemberi Pakan dan Pengatur Suhu Otomatis untuk Ayam Pedaging Berbasis Programmable Logic Controller pada Kandang Tertutup. Skripsi. Universitas Lampung.

Ridhamuttaqin, Aji., Trisanto, Agus., dan Nasrullah, Emir. 2013. Rancang Bangun Model Sistem Pemberi Pakan Ayam Otomatis Berbasis Fuzzy Logic Control. Skripsi. Jurusan Teknik Elektro Fakultas Teknik Universitas Lam

Syafar Muhammad A. 2017. Sistem Pengisian Voucher Listrik Jarak Jauh Via SMS Berbasis Mikrokontroller. Jurnal INSTEK (Informatika Sains dan Teknologi) UIN Alauddin. Vol .2 No. 2 .Oktober.

Syafar Muhammad A. 2016. Kendali Perangkat Listrik dan Monitoring Daya Pada MCB Berbasis TCP/IP. Jurnal INSTEK (Informatika Sains dan Teknologi) UIN Alauddin. Vol .1 No. 1 .Oktober. 